\title{
Price reversals
}

\section{Bid-ask errors or market overreaction?*}

\author{
Gautam Kaul
}

University of Michigan, Ann Arbor, MI 48109, USA

\author{
M. Nimalendran \\ University of Florida, Gainesville, FL 32611, USA
}

Received May 1990, final version received January 1991

\begin{abstract}
We show that bid-ask errors in transaction prices are the predominant source of apparent price reversals in the short run for NASDAQ firms. Once we extract measurement errors in prices caused by the bid-ask spread, we find little evidence of market overreaction. On the contrary, we find that security returns are positively, and not negatively, autocorrelated. We also show that bid-ask errors lead to substantial spurious volatility in transaction returns; about half of measured daily return variances can be induced by the bid-ask effect.
\end{abstract}

\section{Introduction}

Recent empirical research has revealed that stock returns are predictable, in both the short and the long run. One explanation that has received considerable attention is that the stock market 'overreacts' to new information, which in turn leads to price reversals. Such price reversals induce negative autocorrelations in security returns up to some holding period(s) [see, for example, DeBondt and Thaler (1985), De Long et al. (1990), and Shefrin and Statman (1985)]. French and Roll (1986) show that negative

\footnotetext{
${ }^{*}$ We appreciate the comments and suggestions made by Clifford Ball, Victor Bernard, K.C. Chan, Jennifer Conrad, Tom George, Charles Jones, Andrew Karolyi, participants in finance seminars at Ohio State University and the University of Michigan, and especially Jerold Warner (the editor) and Eugene Fama (the referee). We also thank Amy McDonald for preparing the manuscript. Partial funding for this project was provided by the School of Business Administration, University of Michigan.
} 
autocorrelations in short-horizon returns can explain substantial proportions of return variance. For example, as much as $26.9 \%$ of daily return variances of firms in the smallest quintile of the New York and American Stock Exchanges (NYSE and AMEX) can be explained by price reversals. As a more direct consequence of overreaction, Lehmann (1990) and Lo and MacKinlay (1990) show that contrarian strategies based on weekly returns almost always earn significant positive profits.

A!l of these studies, however, rely on transaction prices of NYSE and AMEX firms, and are thus unable to disentangle the effects of price reversals caused by overreaction from those caused by measurement errors in prices. One potentially important source of measurement errors in prices is the existence of bid-ask spreads in securities markets. Neiderhoffer and Osborne (1966) and Roll (1984) show that the bid-ask spread causes price reversals and, hence, negative autocorrelation in security returns.

In this paper, we investigate the relative importance of bid-ask errors and overreaction in determining the time-series properties of short-horizon security returns. The implications of overreaction and measurement errors due to the bid-ask effect are likely to be quite different: the former brings into question the concept of market efficiency, whereas the implications of the latter are largely methodological.

The creation of the National Market System (NMS) in 1982 led to the availability of both end-of-day transaction and bid-ask prices, making our investigation possible. To examine the relative importance of overreaction and bid-ask errors, we construct two sets of returns for NASDAQ firms over the 1983-1987 period: transaction-price-based returns (whicil include bid-ask errors) and bid-to-bid returns (which exclude the bid-ask bounce). Using variance-ratio tests we show that the predominant, if not only, source of price reversals in the short run is the bid-ask effect. There is little evidence of market overreaction. On the contrary, once we extract the measurement errors in prices due to the spread (that is, use bid-to-bid returns), we find that security returns are positively, and not negatively, autocorrelated.

Our evidence for NASDAQ firms provides a puzzling contrast to the short-run behavior of the returns of NYSE and AMEX stocks documented by French and Roll (1986). We attempt to reconcile these differences, but one important puzzle remains: French and Roll find negative autocorrelations up to lag 13 in daily transaction returns of NYSE and AMEX firms, whereas the transaction returns of NASDAQ stocks have negative autocorrelation primarily at lag 1 , and not thereafter. Unfortunately, because bid-ask data for NYSE and AMEX firms are lacking, we are unable to analyze the source(s) of this difference in detail.

Inferences in empirical tests of financial models should be based on the volatility of the 'true', rather than the observed, value of a firm. Accordingly, we also present estimates of the spurious volatility generated by bid-ask 
errors in the measured returns of our NASDAQ sample. We show that bid-ask errors can explain over $50 \%$ of the daily return variances of smallersized firms. Even for the largest firms in our sample, this proportion is as high as $23 \%$. Such a high degree of spurious volatility is likely to reduce the power of tests based on high-frequency transaction returns of individual securities. For example, in event studies that use daily or intraday data, the gains in power achieved by narrowing the event window could be partly offset by more noise in measured returns. Similarly, attempts to explain the variation in high-frequency security returns using economic factors may be unsuccessful [see Roll (1988)] partly because bid-ask errors would lead to a downward bias in both the $t$-statistics of the factors and the $R^{2}$ 's of such regressions.

In section 2, we discuss the issues and hypotheses addressed in this paper. Section 3 describes the methodology in detail, and in section 4 we analyze the empirical evidence and compare our results for NASDAQ firms with the existing evidence for NYSE and AMEX stocks. Section 5 concludes with a brief summary.

\section{The hypotheses}

\subsection{Bid-ask errors versus market overreaction}

In this section, we present a simple model for stock returns that provides a framework for studying the potential impact of bid-ask errors or overreaction on security-return autocorrelations and variances. Let $R_{t}$, the return on particular security in period $t$, be written as

$$
R_{t}=\mu+\eta_{t}
$$

where

$\mu=$ unconditional mean of $R_{t}$ in period $t$,

$\eta_{t}=$ idiosyncratic white noise, where $\eta_{t} \sim \mathrm{N}\left(0, \sigma_{\eta}^{2}\right)$.

Eq. (1) is a representation of the hypothesis that, in an efficient market, stock prices follow a random-walk process, that is, $\operatorname{cov}\left(\eta_{t}, \eta_{t-j}\right)=0$ for all $j \neq 0$. The model in (1) will serve as a benchmark to evaluate the impact of overreaction and/or bid-ask errors on the time-series behavior of returns. If returns are characterized by the model in (1), they will be uncorrelated over time and, consequently, the variance of returns will be linear in the measurement interval for $R_{t}$.

Now consider an alternative model that allows observed returns to contain errors due to the bid-ask spread and/or overreaction by traders to the 
arrival of new information. In particular, consider the following model:

$$
R_{t}=\mu+\eta_{t}+\varepsilon_{t}
$$

where $\varepsilon_{t}$ is the error component induced by the bid-ask spread and/or traders' overreaction.

Bid-ask errors. Let $s$ be the bid-ask spread defined as $\left(P_{\mathrm{A}}-P_{\mathrm{B}}\right) /$ $\frac{1}{2}\left(P_{\mathrm{A}}+P_{\mathrm{B}}\right)$, where $P_{\mathrm{A}}$ and $P_{\mathrm{B}}$ are ask and bid quotes. Then if $\varepsilon_{t}$ is entirely due to bid-ask errors (in transaction prices) that are independent and identically distributed over time, it can be shown [Roll (1984)] that

$$
\begin{aligned}
& \operatorname{cov}\left(\varepsilon_{t}, \varepsilon_{t-j}\right)= \begin{cases}-s^{2} / 4 & \text { if } j=1, \\
0 & \text { otherwise, }\end{cases} \\
& \operatorname{var}\left(\varepsilon_{t}\right)=s^{2} / 2 \\
& \rho_{\varepsilon}=-\frac{1}{2}
\end{aligned}
$$

Eq. (3a) implies that if bid-ask errors in transaction prices are independently distributed over time, they will induce negative autocorrelation in observed returns only at lag 1 . The negative first-order autocovariance will be $s^{2} / 4$. An independently distributed bid-ask error component in prices will, therefore, cause returns to behave like a first-order moving-average process.

Eq. (3b) shows that the variance of the error component will be $s^{2} / 2$, and given (3a) and (3b), the first-order autocorrelation of $\varepsilon_{t}$ will be $-\frac{1}{2} .^{1}$ The absolute magnitude of the first-order autocorrelation of transaction returns, however, will be less than $\frac{1}{2}$, because var $\left(\eta_{t}\right)>0$. Of course, if bid-ask errors are not independent over time, they can induce autocorrelations beyond lag 1 , resulting in a higher-order moving-average process for returns.

Market overreaction. If $\varepsilon_{t}$ is due solely to mispricing errors caused by traders' overreaction to the arrival of new information, observed returns will be negatively autocorrelated up to some unspecified higher-order

\footnotetext{
${ }^{1}$ If there is adverse selection in securities markets, the above analysis will be altered [see Glosten (1987)]. Since George, Kaul, and Ninalendran (1990) present evidence that the adverse-selection component of quoted spreads is small, however, we do not model this component of the spread. [See section 4.4 for further discussion of this issue.]
} 
lags, that is,

$$
\operatorname{cov}\left(\varepsilon_{t}, \varepsilon_{t-j}\right)<0, \quad \forall j=1,2,3, \ldots
$$

All existing 'theories' of overreaction imply this behavior. For example, French and Roll (1986) indicate that '... unless market prices are unrelated to the objective economic value of the stock, pricing errors must be corrected in the long run' (p. 15). Such correction will, in turn, lead to negative autocorrelations in security returns up to some arbitrarily specified lag. Lo and MacKinlay (1990) argue that autocorrelations due to overreaction will in general be negative, at least at lag 1 , if the duration of one period corresponds to a complete cycle of overreaction. ${ }^{2}$ Unfortunately, there is no model for overreaction that characterizes the negative autocorrelations generated in security returns more explicitly.

Observed returns could contain measurement errors due to both overreaction and the bid-ask spread. ${ }^{3}$ However, given that only actual transaction prices have typically been available for most traded stocks, past studies have been able to estimate only the combined importance of errors in short-horizon returns. There is some indirect evidence that traders overreact to new information. For example, French and Roll (1986, table 3) find that security returns are weakly negatively autocorrelated at lags 1 through 13 . Also, Lehmann (1990) and Lo and MacKinlay (1990) show that contrarian strategies based on short-horizon (weekly) returns almost always earn significant positive profits. None of these studies, however, provide direct estimates of the relative importance of bid-ask errors and market overreaction in generating stock-price reversals.

We investigate this relative importance using the end-of-day transaction and bid-ask prices for NASDAQ stocks available since 1982. We define $R_{\mathrm{T}}$ and $R_{\mathrm{B}}$ as returns calculated using transaction prices and bid prices, respectively. $R_{\mathrm{T}}$ contains pricing errors due to both market overreaction and the bid-ask spread. Since $R_{\mathrm{B}}$ is constructed using only bid-to-bid prices, however, it will not contain any errors due to the bid-ask spread. We can thus construct tests to evaluate the time-series properties of both $R_{\mathrm{T}}$ and $R_{\mathrm{B}}$, and obtain a direct estimate of the relative importance of market overreaction and bid-ask errors.

\footnotetext{
${ }^{2}$ Lo and MacKinlay also show that analyses of 'fads' [Summers (1986)] or time-varying expected returns [Fama and French (1988) and Poterba and Summers (1988)] that typically model prices as a sum of a random walk and a stationary process do not necessarily imply negative autocorrelations at all lags. Hence, stock-market 'fads' may not necessarily imply positive profits from contrarian strategies, whereas overreaction always does.

${ }^{3}$ Nonsynchronous trading and price discreteness can also lead to measurement errors and negative autocorrelations in returns. The effect is likely to be small, however [see, for example, Scholes and Williams (1977)].
} 
Finally, the availability of both transaction and bid-ask prices allows us to study the properties of the errors in transaction returns caused by the bid-ask spread. The difference between transaction and bid returns, $R D_{t}$, is a direct measure of bid-ask errors. Specifically,

$$
R D_{t}=R_{\mathrm{T} t}-R_{\mathrm{B} t}=B A_{t},
$$

where $B A_{t}$ are the errors in transaction returns due to the bid-ask spread.

In section 4.4 we analyze in detail the time-series properties of the bid-ask error component of transaction returns, $R D_{t}$, and the relative contribution of this component to the variance of daily and multiday transaction returns.

\section{The methodology}

\subsection{Variances and autocorrelations using return data}

We use the variance-ratio test to determine the relative magnitudes of errors caused by overreaction and the bid-ask spread in daily stock returns. This methodology has been used in recent studies by French and Roll (1986), Lo and MacKinlay (1988), Fama and French (1988), and Poterba and Summers (1988). Cochrane (1988) and Lo and MacKinlay (1989) provide detailed analyses of the properties of the variance-ratio test statistic, and stress its relative power compared with alternative test statistics, even in small samples.

We study the variability of a $k$-period return in relation to the variation in a daily return. Let $\operatorname{VR}(k)$ be the ratio of the variance of a $k$-period return to $k$ times the variance of a one-period return. Specifically

$$
\operatorname{VR}(k)=\left(\frac{1}{k}\right)\left\{\frac{\operatorname{var}\left(R_{t}^{k}\right)}{\operatorname{var}\left(R_{t}\right)}\right\},
$$

where

$R_{t}=$ return for day $t$,

$R_{t}^{k}=$ return for a $k$-period interval at day $t$.

Cochrane (1988) and Lo and MacKinlay (1988) show that VR( $k$ ) can be written as a function of estimated autocorrelations of returns measured over the basic measurement interval (daily in our case). In particular,

$$
\operatorname{VR}(k) \simeq 1+\frac{2(k-1)}{k} \hat{\rho}_{1}+\frac{2(k-2)}{k} \hat{\rho}_{2}+\cdots+\frac{2}{k} \hat{\rho}_{k-1},
$$


where $\hat{\rho}_{j}$ denotes the $j$ th-order autocorrelation coefficient estimator of daily returns, $R_{t}$.

Eq. (7) provides an intuitive interpretation for the variance ratio computed for a $k$-period interval: it is approximately the weighted average of the first $k-1$ autocorrelation coefficient estimators of daily returns, with arithmetically declining weights. The intuition becomes clear if we consider our benchmark model in (1): if stock prices follow a random walk, returns will be uncorrelated and hence $\mathrm{E}[\mathrm{VR}(k)]=1$. In other words, if returns are uncorrelated, the $k$-period return variance should be $k$ times the one-period return variance. On the other hand, variance ratios will be less than unity if transaction returns contain errors due to the bid-ask spread or if traders overreact to new information, and the overreaction is eventually corrected.

To distinguish between the relative impact of bid-ask errors, and overreaction on security returns we estimate the variance ratio in (6) for different measurement intervals, $k$, using both transaction and bid returns, $R_{\mathrm{T}}$ and $R_{\mathrm{B}}$, respectively. Recall that $R_{\mathrm{T}}$ contains bid-ask errors whereas $R_{\mathrm{B}}$ does not. Variance-ratio estiamtes based on $R_{\mathrm{T}}$ will measure the combined contribution of bid-ask errors and overreaction to return variances. Consequently, these estimates are likely to be less than unity. On the other hand, variance ratios based on $R_{\mathrm{B}}$ will be purged of any effects of price reversals due to the bid-ask effect, and the extent to which these ratios depart from unity will provide a direct measure of the importance of overreaction in securities markets.

To complement the variance-ratio analysis we also estimate daily autocorrelations of $R_{\mathrm{T}}$ and $R_{\mathrm{B}}$. Since market overreaction is consistent with negative autocorrelations in returns up to some arbitrary $\operatorname{lag}(\mathrm{s})$, the variance-ratio statistic may be a more powerful tool for detecting reversals in stock prices. On the other hand, if bid-ask errors are the sole source of negative autocorrelation in returns, the autocorrelation analysis would be more powerful. This follows because if bid-ask errors in transaction prices are independent and identically distributed, autocorrelation in returns will occur only at lag 1 . The autocorrelation analysis should, therefore, provide some additional insights.

\subsection{Variances and autocorrelations using bid-ask errors}

To study the time-series behavior of the bid-ask errors and, more importantly, to evaluate their contribution to the variance of daily and multiday returns, we conduct two sets of tests using the bid-ask error variable, $R D_{t}$ [see (5) j. First, we estirnate daily autocorrelations of $R D_{t}$ up to lag 10 to determine whether bid-ask errors in transaction prices are independent over time and, consequently, whether the first-order autocorrelation of $R D_{t}$ is $-\frac{1}{2}$. 
Second, we determine the contribution of bid-ask errors to the volatility of short-horizon transaction returns by estimating the following variance ratio:

$$
\operatorname{VRD}(k)=\frac{\operatorname{var}\left(R D_{t}^{k}\right)}{\operatorname{var}\left(R_{T t}^{k}\right)} \quad \text { where } \quad k=1,2,3, \ldots
$$

Since we are interested in the contribution of bid-ask errors to the variance of transaction returns over different measurement intervals, we estimate $\operatorname{VRD}(k)$ for different $k$. Moreover, unlike the earlier variance ratio, $\operatorname{VR}(k)$, we estimate $\operatorname{VRD}(k)$ for a daily measurement interval also (that is, for $k=1$ ). Since the spurious volatility generated by bid-ask errors does not vary with the measurement interval of returns, the degree of noise in short-horizon (for example, daily) returns will be much larger than that in long-horizon (say, six-month) transaction returns. Also, the one-day estimates of $\operatorname{VRD}(k)$ have the additional advantage of providing upper bounds on the proportion of spurious volatility in intraday returns, the use of which is becoming increasingly prevalent.

\section{The evidence}

\subsection{Data description}

We use the Center for Research in Security Prices (CRSP) daily master file for NASDAQ/NMS firms to compute security returns. Trading on the NMS during 1982 (the first year of the NMS system) was limited to only the most actively traded stocks (about 40). Hence, we use data from January 1983 to December 1987. Since we require an unbroken series of actual trading-transaction prices and bid-ask quotes on a daily basis, we break up the five-year sample period into ten six-month subperiods. Increasing the length of the subperiods reduces the number of sampled securities substantially. Since we are interested in the short-run behavior of returns, however, a six-month subperiod has enough daily observations to calculate variance ratios up to a 12-week (overlapping) measurement interval. Furthermore, Monte Carlo simulations by Lo and MacKinlay (1989b) show that even for sample sizes as small as 32 , the variancc-ratio test provides reliable inferences.

We sort all the sampled securities into three portfolios based on market value (number of shares outstanding times price per share) at the beginning of each subperiod. The smallest, intermediate, and largest firms are contained in portfolios 1,2 , and 3 . Splitting firms into more than three portfolios significantly reduces the sample sizes of the smaller-sized portfolios. For each security, we calculate three sets of returns: transaction returns, $R_{\mathrm{T} t}$, bid-to-bid returns, $R_{\mathrm{B} t}$, and the difference between transaction and bid returns, $R D_{t}$. 
These three series, calculated for daily and multiday intervals, form the basis of all the tests in this paper.

\subsection{Some descriptive statistics}

Table 1 reports some descriptive statistics for the NASDAQ firms in our sample. The table contains average estimates of market value (in million dollars), transaction prices, quoted spreads (in percent), and trading volume (in thousands) for securities belonging to each portfolio, and for all firms in our sample. The quoted spread, reported in percent, is calculated as $\left(P_{\mathrm{A}}-\right.$ $\left.P_{\mathrm{B}}\right) / \frac{1}{2}\left(P_{\mathrm{A}}+P_{\mathrm{B}}\right)$, where $P_{\mathrm{A}}$ and $P_{\mathrm{B}}$ are the ask and bid prices. All reported numbers are based on daily estimates at the beginning of each subperiod. The individual-firm values are averaged across firms within each portfolio (and across all firms in the sample) to obtain subperiod averages. Each reported summary statistic is the weighted grand average of the ten subperiod averages. Since the number of firms varies over the subperiods, the grand averages are obtained by weighting each subperiod's average by the number of firms in that subperiod.

As a result of our sampling procedure, which requires a firm to have an unbroken series of actual daily transaction and bid-ask prices within a particular subperiod, the NASDAQ sample contains fairly large firms. Based on comparable-year market values of NYSE and AMEX firms, we find that

Table 1

Descriptive statistics for NASDAQ stocks, 1983-1987.

Average market value (number of shares outstanding times price per share), transaction price, quoted spread, and trading volume for all securities and securities belonging to three portfolios formed by rankings of market value of equity outstanding at the beginning of each six-month period. The quoted spread, reported in percent, is calculated as $\left(P_{\mathrm{A}}-P_{\mathrm{B}}\right) / \frac{1}{2}\left(P_{\mathrm{A}}+P_{\mathrm{B}}\right)$, where $P_{\mathrm{A}}$ and $P_{\mathrm{B}}$ are the ask and bid prices at the end of the trading day. All reported numbers are based on daily estimates at the beginning of each of the ten six-month subperiods. The individual-firm statistics are averaged across firms within each portfolio (and across all firms in the sample) to obtain subperiod averages. Each reported summary statistic is the grand average of the ten subperiod averages. Since the number of firms varies over the subperiods, the grand averages are obtained by weighting each subperiod average by the number of firms in that subperiod.

\begin{tabular}{lcccc}
\hline $\begin{array}{l}\text { NASDAQ } \\
\text { portfolios }\end{array}$ & $\begin{array}{c}\text { Average market } \\
\text { value } \\
\text { (in million dollars) }\end{array}$ & $\begin{array}{c}\text { Average } \\
\text { price } \\
\text { (in dollars) }\end{array}$ & $\begin{array}{c}\text { Quoted } \\
\text { spread } \\
(\%)\end{array}$ & $\begin{array}{c}\text { Average } \\
\text { volume } \\
\text { (in thousands) }\end{array}$ \\
\hline 1 (smallest) & 27.191 & 7.037 & 4.278 & 25.981 \\
2 (largest) & 69.599 & 11.931 & 2.554 & 36.020 \\
All firms & 400.921 & 29.228 & 1.372 & 95.964 \\
\hline
\end{tabular}


the NASDAQ sample has an average market value comparable to the average firm on the New York and American Stock Exchanges. This occurs because, although we do not have very large firms on the NASDAQ, our sampling procedure excludes the very small NASDAQ firms. Similar conclusions can be arrived at by comparing other sample characteristics of the NASDAQ firms with NYSE and AMEX firms. Since the spurious volatility and negative autocorrelations induced by bid-ask errors are directly related to the spread [see (3a) and (3b)], the quoted spreads of our sample of firms are of particular importance. The average bid-ask spreads of the securities in our sample range between $4.28 \%$ and $1.37 \%$, with an average value of $2.24 \%$ for all firms. Using Keim's (1989) data, the average spread of NYSE and AMEX firms at the end of 1988 is $2.82 \%$. Even in spread estimates, therefore, our sample contains firms comparable to NYSE and AMEX firms, and hence allows us to generalize the findings of this paper.

\subsection{Overreaction or bid-ask errors}

\subsubsection{Variance ratio tests: Procedure}

Tables 2 and 3 report variance ratio estimates based on daily transaction and bid returns, for measurement intervals up to 12 weeks ( 84 days). The

Table 2

Variance ratios for NASDAQ stocks using transaction returns, 19831987.

Variance ratios are based on daily returns of all securities and securities belonging to three portfolios formed by rankings of market value of equity outstanding at the beginning of each six-month period. The variance ratio statistic is defined as $\operatorname{VR}(k)=(1 / k)\left\{\operatorname{var}\left(R^{k}\right) / \operatorname{var}(R)\right\}$, where $R$ and $R^{k}$ denote returns over a daily and a $k$-period measurement interval, respectively. Each variance ratio is corrected for small-sample biases (see appendix). All statistics are estimated for each firm, using overlapping data to calculate the $k$-period variance, during each of the ten six-month subperiods between January 1983 and December 1987. The individual-firm statistics are averaged across firms within each portfolio (and across all firms in the sample) to obtain subperiod averages. Each reported summary statistic is the weighted grand average of the ten subperiod averages. The numbers in parentheses are weighted standard errors based on the distribution of the subperiod averages.

\begin{tabular}{lccccc}
\hline $\begin{array}{l}\text { NASDAQ } \\
\text { portfolios }\end{array}$ & $\begin{array}{c}\text { Return measurement interval }(k) \\
\text { week }\end{array}$ & $\begin{array}{c}2 \\
\text { week }\end{array}$ & $\begin{array}{c}4 \\
\text { week }\end{array}$ & $\begin{array}{c}8 \\
\text { week }\end{array}$ & $\begin{array}{c}12 \\
\text { week }\end{array}$ \\
\hline 1 & 0.656 & 0.670 & 0.705 & 0.776 & 0.798 \\
(smallest) & $(0.021)$ & $(0.024)$ & $(0.034)$ & $(0.061)$ & $(0.075)$ \\
2 & 0.742 & 0.774 & 0.811 & 0.890 & 0.905 \\
& $(0.015)$ & $(0.018)$ & $(0.027)$ & $(0.065)$ & $(0.090)$ \\
3 & 0.873 & 0.933 & 0.986 & 1.093 & 1.062 \\
(largest) & $(0.013)$ & $(0.021)$ & $(0.020)$ & $(0.056)$ & $(0.088)$ \\
All firms & 0.794 & 0.837 & 0.882 & 0.973 & 0.966 \\
& $(0.018)$ & $(0.022)$ & $(0.025)$ & $(0.041)$ & $(0.054)$ \\
\hline
\end{tabular}


Table 3

Variance ratios for NASDAQ stocks using bid-to-bid returns, 1983-1987.

Variance ratios are based on daily returns of all securities and securities belonging to three portfolios formed by rankings of market value of equity outstanding at the beginning of each six-month period. The variance ratio statistic is defined as $\operatorname{VR}(k)=(1 / k)\left\{\operatorname{var}\left(R^{k}\right) / \operatorname{var}(R)\right\}$, where $R$ and $R^{k}$ denote returns over a daily and a $k$-period measurement interval, respectively. Each variance ratio is corrected for small-sample biases (see appendix). All of the statistics are estimated for each firm, using overlapping data to calculate the $k$-period variance, during each of the ten six-month subperiods between January 1983 and December 1987. The individual-firm statistics are averaged across firms within each portfolio (and across all firms in the sample) to obtain subperiod averages. Each reported summary statistic is the weighted grand average of the ten subperiod averages. The numbers in parentheses are weighted standard errors based on the distribution of the subperiod averages.

\begin{tabular}{lccccc}
\hline & \multicolumn{5}{c}{ Return measurement interval $(k)$} \\
\cline { 2 - 6 } $\begin{array}{l}\text { NASDAQ } \\
\text { portfolios }\end{array}$ & $\begin{array}{c}1 \\
\text { weck }\end{array}$ & $\begin{array}{c}2 \\
\text { weck }\end{array}$ & $\begin{array}{c}4 \\
\text { week }\end{array}$ & $\begin{array}{c}8 \\
\text { week }\end{array}$ & $\begin{array}{c}12 \\
\text { week }\end{array}$ \\
\hline $\mathbf{1}$ & 0.932 & 0.993 & 1.065 & 1.161 & 1.183 \\
(smallest) & $(0.026)$ & $(0.028)$ & $(0.048)$ & $(0.094)$ & $(0.116)$ \\
2 & 0.950 & 1.017 & 1.079 & 1.183 & 1.195 \\
& $(0.009)$ & $(0.015)$ & $(0.031)$ & $(0.085)$ & $(0.121)$ \\
3 & 1.009 & 1.096 & 1.170 & 1.300 & 1.259 \\
(largest) & $(0.013)$ & $(0.023)$ & $(0.027)$ & $(0.067)$ & $(0.107)$ \\
All firms & 0.976 & 1.053 & 1.122 & 1.238 & 1.225 \\
& $(0.010)$ & $(0.015)$ & $(0.021)$ & $(0.047)$ & $(0.066)$ \\
\hline
\end{tabular}

variance ratios compare $k$-period variances to a one-period variance. In calculating daily variances we use returns of actual trading days only, thus excluding all multiday returns (that is, weekends and holidays). To increase the power of our tests, we use overlapping $k$-period returns to estimate the $k$-period variances (that is, the numerator of the variance ratios). In addition, all reported variance ratios are corrected for two important small-sample biases. The first bias correction is a degrees-of-freedom correction to obtain unbiased estimators of the one-period and $k$-period variances. The second correction is to obtain unbiased estimates of the variance ratios. Even under the assumption of serially independent one-period returns, the estimated variance ratios will be less than unity because $\mathrm{E}\left(\hat{\rho}_{j}\right)<0$ [see (7)]. Details of the corrections are discussed in the appendix. Botin small-sample biases cause variance ratios to be substantially downward-biased, particularly when the measurement interval, $k$, increases with respect to the sample size.

The procedure used to compute the reported statistics is similar to the one used in table 1 . Specifically, the variance ratios are estimated for each firm during a particular subperiod. The individual-firm statistics are then averaged across firms in each portfolio (and across all firms in the sample) to obtain subperiod averages. Each reported number is the weighted grand average of the ten subperiod averages, where the weights are the number of firms in a 
particular subperiod. Tables 2 and 3 also include weighted standard errors of the variances ratios, which are based on the distribution of the subperiod averages, under the assumption that these averages are independent and identically distributed. This procedure, which is similar to the one used by French and Roll (1986), is used to calculate all the estimates reported in this paper.

\subsubsection{Results}

Transaction-return-based variance-ratio estimates are presented in table 2 . The variance ratios are typically less than unity, which suggests that security returns contain an important negatively autocorrelated component. For example, the one-week variance-ratio estimates range between 0.656 and 0.873 , with an average of 0.794 for all firms. This suggests that a seven-day return variance is substantially (and statistically) less than seven times the daily variance.

The relation between the estimated variance ratios and the length of the measurement interval provides an interesting insight into the behavior of short-horizon returns. For securities within each portfolio, table 2 indicates that the variance ratios increase as the measurement interval, $k$, increases from 1 week to 12 weeks. And, except for the smallest firms (portfolio 1), the 8- and 12-week variance ratios are not statistically different from unity. This pattern of increasing variance ratios suggests that although individual security returns contain a negatively autocorrelated component, its effects are dominated by a positively autocorrelated component as the observation interval increases.

The results in table 2 , though informative, do not provide any insights into the source of the negative autocorrelation in security returns. In table 3 we therefore present variance-ratio estimates based on bid returns, $R_{\mathrm{B} t}$. These returns do not contain errors due to the bid-ask spread and provide direct evidence about the relative importance of overreaction and bid-ask errors in determining the behavior of observed returns. The reported variance ratios in table 3 are typically greater than or equal to unity. There is some evidence of negative autocorrelation (and, therefore, overreaction) at the one-week interval. With the exception of the largest firms in our samplc (portfolio 3), the one-week variance ratios are statistically less than unity. The economic magnitudes of the departures from unity are small, however, especially in comparison with the evidence based on transaction returns. For all firms in the sample, the one-week variance ratio is 0.976 , compared with 0.794 for transaction returns. In the appendix we provide evidence suggesting that the one-week variance ratios of $R_{\mathrm{B} t}$ are less than unity because the per-day variance of returns over weekends is substantially less than the variance of a 
typical trading-day return.

The behavior of the variance-ratio estimates (in table 3) at measurement intervals greater than one week is consistent with the findings in table 2 . Variance ratios for firms in all three portfolios increase as $k$ increases. In fact, for $k>2$ weeks the variance-ratio estimates are typically statistically greater than unity. This suggests positive, and not negative, autocorrelations in security returns.

The results in table 2 and 3 have major implications for the relative importance of bid-ask errors and overreaction in securities markets. First, there is little evidence in favor of market overreaction. There is some evidence for price reversals using bid-to-bid returns at the one-week interval. In the appendix, however, we show that even this evidence is not consistent with market overreaction. ${ }^{4}$ Second, the behavior of variance ratios at increasing intervals in fact suggests that returns are positively autocorrelated. Positive autocorrelation in short-horizon returns is quite contrary to the predictions of models of market overreaction, but is consistent with timevarying expected returns [Conrad, Kaul, and Nimalendran (1990)] or partial price adjustments [Cohen et al. (1986) and Amihud and Mendelson (1987)].

Finally, the comparative behavior of variance ratios based on transaction versus bid returns suggests that bid-ask errors in security prices are the predominant source of price reversals in securities markets. Also, the relative magnitudes of variance ratios in tables 2 and 3 , at each observation interval, show that bid-ask errors may be a nontrivial component of observed security returns. For example, for all firms in the sample the 1- to 12 -week variance ratios based on transaction returns range between 0.794 and 0.966 . On the other hand, the variance ratios based on bid returns range between 0.976 and 1.225. A more detailed analysis of the importance of bid-ask errors in observed security prices is provided in section 4.4 .

\subsubsection{Autocorrelations: Procedure}

To complement the variance-ratio analysis, we estimate daily autocorrelations up to lag 10 for transaction and bid returns. The evidence is presented in tables 4 and 5. All autocorrelations are adjusted for small-sample bias (see appendix), and the reporting procedure is identical to the one used in

\footnotetext{
${ }^{4}$ The variance ratios reported in this paper use the estimated mean of every set of $k$-period returns in calculating the $k$-period variances. This procedure could lead to biases in small samples [see Cochrane (1988)]. We also estimate the variance ratios using $k$ times the daily mean, $k \hat{\mu}$, instead of the $k$-period mean, $\hat{\mu}^{k}$, in calculating the $k$-period variances. All of these alternative variance-ratio estimates are greater than the corresponding ratios reported in the paper. In fact, the one-week variance ratios based on bid returns are not significantly different from unity.
} 


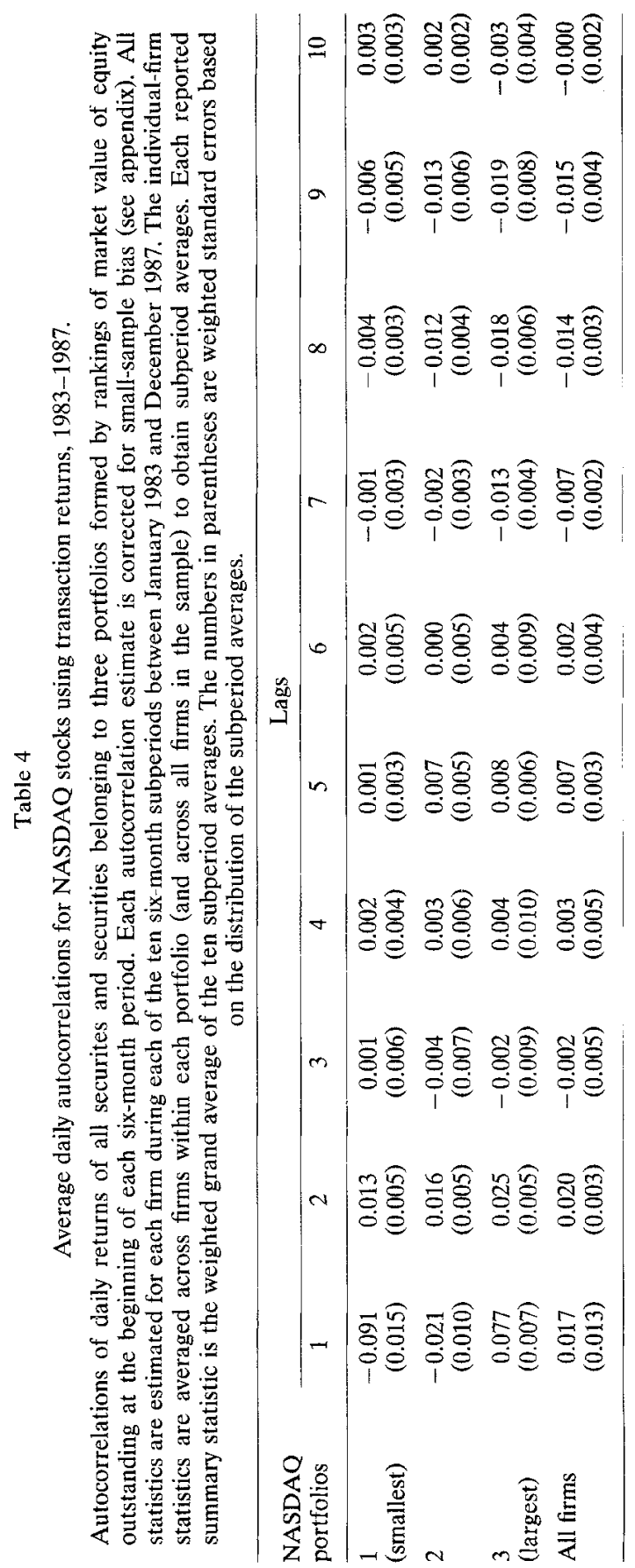




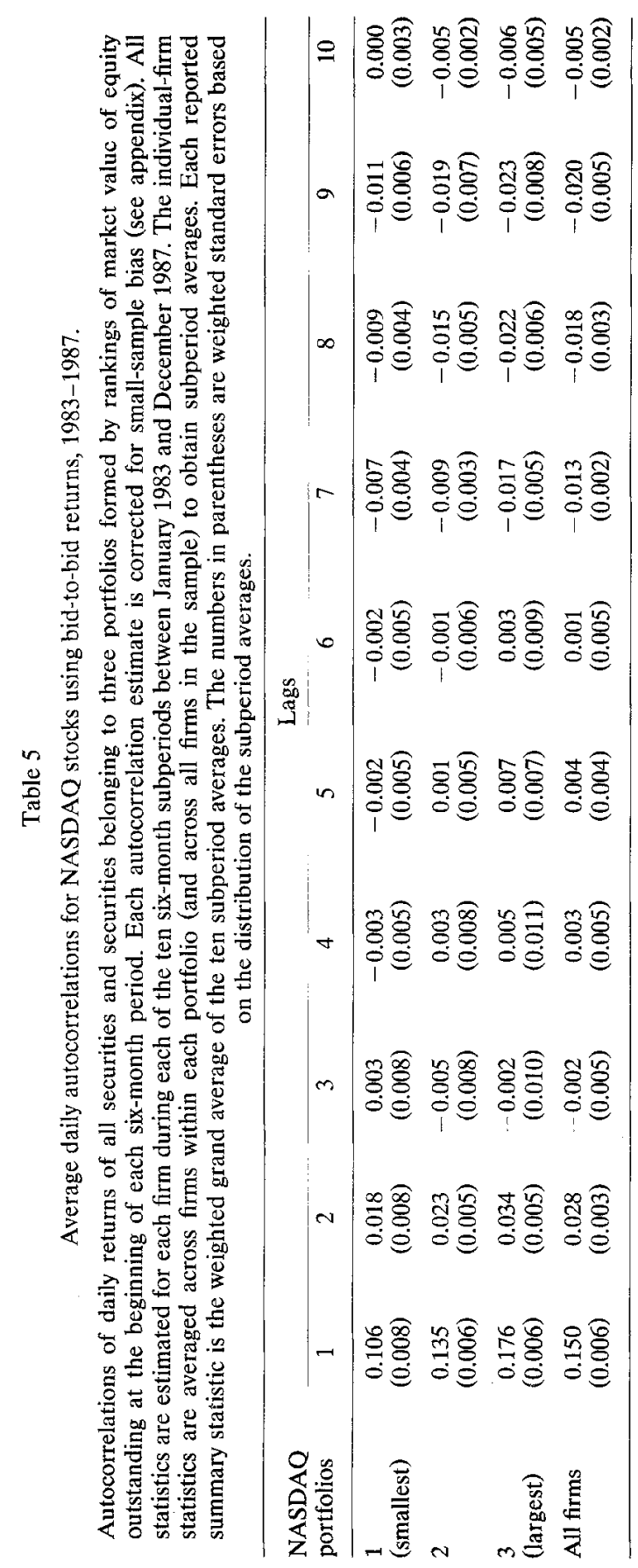


previous tables. The evidence in tables 4 and 5, however, is not directly (or perfectly) comparable to the results in tables 2 and 3 . In estimating daily autocorrelations we have to use multiday returns to obtain an unbroken series of returns. The denominators of the variance ratios, however, are based on actual trading-day returns. Also, we cannot compare the variance ratios for long (more than two-week) intervals with the autocorrelation estimates because autocorrelations beyond lag 10 (which are implicitly weighted in the variance ratios) are not provided. It is impractical and inefficient to estimate autocorrelations beyond a certain reasonable lag, especially since the variance-ratio analysis is a more powerful technique for identifying the time-series behavior of returns. Hence, the evidence in tables 4 and 5 should not be compared literally with the variance-ratio analysis, but should be evaluated for general patterns.

\subsubsection{Results}

The autocorrelations of transaction and bid returns are broadly consistent with the findings reported in tables 2 and 3 . Transaction returns have negative autocorrelations primarily at $\operatorname{lag} 1$, especially for smaller securities. Higher-order autocorrelations are occasionally significantly negative (for example at lags 8 and 9), but are typically small. On the other hand, bid returns are significantly positively autocorrelated at lags 1 and 2 , with occasional significantly negative autocorrelations at lags 8 and 9 . Note, in particular, the relatively large positive autocorrelations at lag 1 for securities belonging to all three portfolios. For example, the average first-order autocorrelation for all firms in the sample is 0.15 , and several standard errors from zero. These findings again suggest that the predominant source of reversals in short-run security prices is bid-ask errors. There is little evidence of market overreaction; in fact the positive autocorrelations in $R_{\mathrm{B} t}$ provide evidence to the contrary.

\subsection{The importance of bid-ask errors}

\subsubsection{Autocorrelations in bid-ask errors in transaction returns}

The importance of bid-ask errors in short-horizon security prices is suggested by the variance-ratio and autocorrelation analysis presented above. Since we can observe both transaction and bid-ask prices for NASDAQ firms, we can directly measure the properties of the bid-ask errors in transaction returns by analyzing the time-series behavior of $R D_{t}$ [see (5)]. In table 6 we present the daily autocorrelations of the bid-ask error variable, $R D_{t}$. The use of multiday returns does not affect the estimated autocorrela- 


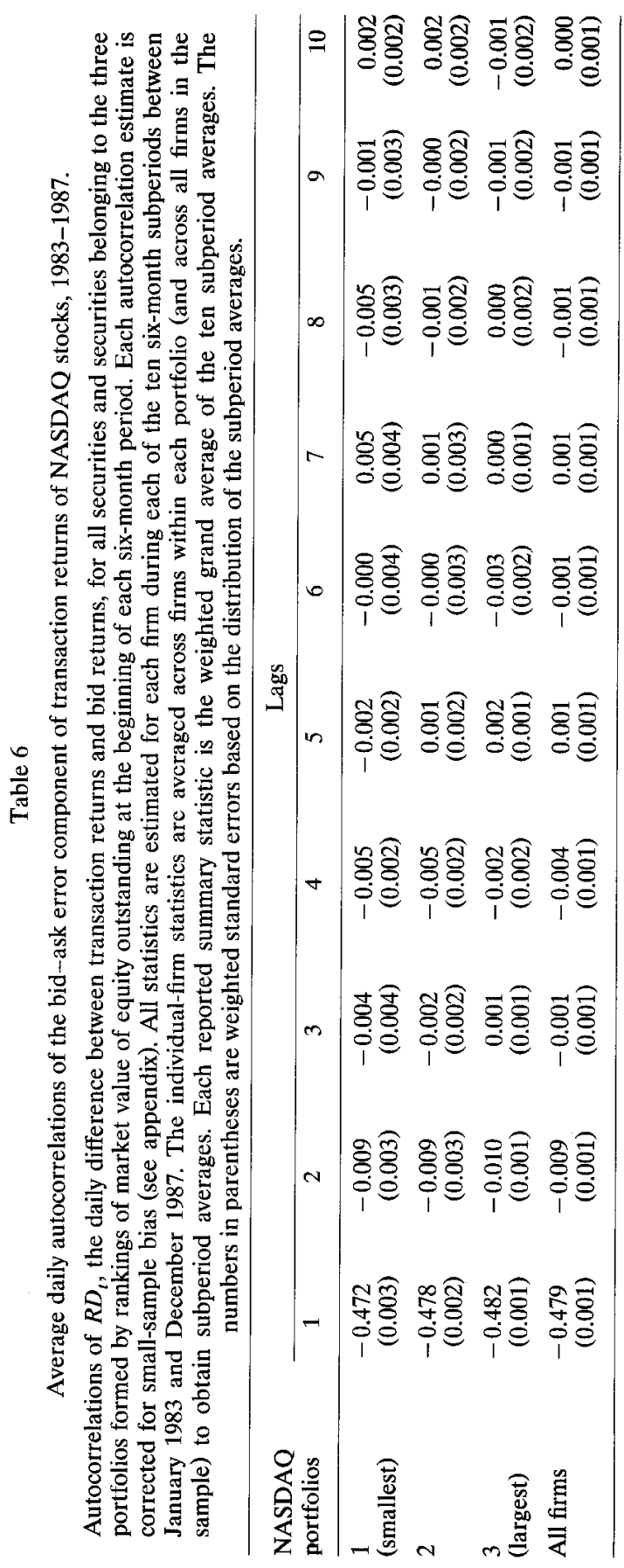


Table 7

The relative importance of bid-ask errors for NASDAQ stocks, 1983-1987.

Ratios of the variance of the bid-ask errors (measured as the difference between transaction and bid returns, $R D_{t}$ ) to the variance of transaction returns, $R_{\mathrm{T} t}$, i.e., $\operatorname{var}\left(R D_{t}^{k}\right) / \operatorname{var}\left(R_{\mathrm{T} t}^{k}\right)$, for all securities and securities belonging to three portfolios formed by rankings of market value of equity outstanding at the beginning of each six-month period. The variance ratios are corrected for small-sample bias (see appendix). All statistics are estimated for each firm, using overlapping data to calculate the $k$-period variance of bid-ask errors, during each of the ten six-month subperiods between January 1983 and December 1987. The individual-firm statistics are averaged across firms within each portfolio (and across all firms in the sample) to obtain subperiod averages. Each reported summary statistic is the weighted grand average of the ten subperiod averages. The numbers in parentheses are weighted standard errors based on the distribution of the subperiod averages.

\begin{tabular}{lccccccc}
\hline NASDAQ & \multicolumn{7}{c}{ Return measurement interval $(k)$} \\
portfolios & $\begin{array}{c}1 \\
\text { day }\end{array}$ & weekends & $\begin{array}{c}1 \\
\text { week }\end{array}$ & $\begin{array}{c}2 \\
\text { week }\end{array}$ & $\begin{array}{c}4 \\
\text { week }\end{array}$ & $\begin{array}{c}8 \\
\text { week }\end{array}$ & $\begin{array}{c}12 \\
\text { week }\end{array}$ \\
\hline 1 & 0.517 & 0.576 & 0.167 & 0.098 & 0.062 & 0.045 & 0.039 \\
(smallest) & $(0.024)$ & $(0.031)$ & $(0.011)$ & $(0.007)$ & $(0.005)$ & $(0.004)$ & $(0.004)$ \\
2 & 0.384 & 0.423 & 0.102 & 0.057 & 0.034 & 0.024 & 0.022 \\
& $(0.015)$ & $(0.025)$ & $(0.006)$ & $(0.004)$ & $(0.002)$ & $(0.002)$ & $(0.002)$ \\
3 & 0.232 & 0.255 & 0.051 & 0.027 & 0.016 & 0.011 & 0.010 \\
(largest) & $(0.011)$ & $(0.019)$ & $(0.003)$ & $(0.002)$ & $(0.001)$ & $(0.001)$ & $(0.001)$ \\
All firms & 0.329 & 0.363 & 0.087 & 0.049 & 0.029 & 0.021 & 0.019 \\
& $(0.021)$ & $(0.026)$ & $(0.008)$ & $(0.005)$ & $(0.003)$ & $(0.002)$ & $(0.002)$ \\
\hline
\end{tabular}

tions of $R D_{t}$, because both the autocovariances and the variance of $R D_{t}$ will be identical for daily or multiday intervals.

From table 6, first-order autocorrelations of $R D_{t}$ are very similar across firms, and are statistically less than 0.50 . The autocorrelations in table 6 suggest that bid-ask errors in transaction prices may not be independent over time. The average autocorrelation for all firms in our sample is -0.479 . The second-order autocorrelations are also negative and statistically different from zero. However, they are small. ${ }^{5}$

\subsubsection{Spurious volatility generated by bid-ask errors}

Table 7 reports the relative contribution of the bid-ask error component, $R D_{t}$, to the volatility of transaction returns. We estimate the variance ratio in

\footnotetext{
${ }^{5} \mathrm{~A}$ nonindependent bid-ask error in security prices could potentially lead to positive profits from contrarian strategies in which weights beyond lag 1 are used in constructing the arbitrage portfolios. Of course, this conjecture requires a detailed investigation, especially since the correlation in bid-ask errors over time does not appear to be large: the first-order autocorrelations are not very different from 0.50 in economic magnitude, and the second-order autocorrelations are small. Such an investigation, however, is beyond the scope of this paper, but is the topic of further study [see Conrad, Gultekin, and Kaul (1990)].
} 
(8), VRD $(k)$, for measurement intervals of one day, three days (weekends only), one week, .., 12 weeks. The estimates presented in table 7 provide rather striking results. Bid-ask errors in prices lead to substantial overestimation of the volatility of returns. Since use of daily, and even intraday, returns is becoming increasingly common, the one-day variance ratios are particularly important. Bid-ask errors are the source of between $23.2 \%$ and $51.7 \%$ of the variance of daily transaction returns. For all firms in the sample, this proportion is as high as $33 \% .^{6}$ A large fraction of the volatility of measured returns over weekends is again due to bid-ask errors. The contribution of $R D_{t}$ to security-return variances declines steadily as the measurement interval increases. Even for weekly returns, however, the contribution of bid-ask errors to the volatility of returns is nontrivial.

The results in table 7 , and the preceding discussion, indicate the substantial spurious volatility generated by bid-ask errors, especially in daily NASDAQ security returns. Since our sample of NASDAQ stocks contains fairly large firms, we can make some generalizations about the likely importance of bid-ask errors in determining the behavior of short-horizon returns of NYSE and AMEX firms. Recall that the spurious autocorrelation and volatility generated by bid-ask errors is directly related to (the square of) the spread [see (3a) and (3b)]. Our firms have average spreads ranging from $4.28 \%$ and $1.37 \%$ for the smallest to the largest firms, respectively, with an average value of 2.24\%. Based on Keim's (1989) data on spreads for NYSE and AMEX firms at the end of 1988, the average spreads of NYSE and AMEX firms are $1.39 \%$ and $4.66 \% .^{7}$ Hence, given our findings in table 7 , it is likely that, on average, bid-ask errors contribute between $23 \%$ and $33 \%$ of the volatility of daily returns of NYSE firms and over $52 \%$ of the daily volatility of AMEX firms. Moreover, 700 NYSE and AMEX firms have an average spread of more than $6 \%$. For these firms the spurious volatility is likely to be significantly larger than $50 \%$.

\footnotetext{
${ }^{6}$ Estimates of VRD $(k)$ in table 7 are upward-biased because transaction prices and bid-ask quotes on the NASDAQ tapes are measured nonsynchronously. We calculate alternative estimates of $\operatorname{VRD}(k)$ as $\left(s^{2} / 2\right) / \operatorname{var}\left(R_{\mathrm{T} t}\right)$ [see (3b)] for each firm, and then obtain grand averages for all firms and firms within each portfolio. These estimates, though systematically less than those reported in table 7, remain large. Since our objective is to provide an approximate idea of the extent of spurious volatility generated by bid-ask errors, we do not report these alternative estimates. Detailed results may be obtained from the authors.

${ }^{7}$ We are grateful to Donald Keim for providing the data necessary to make these calculations. Keim's sample includes 1,618 NYSE and 814 AMEX firms on December 23, 1988, obtained from the Bridge Trading Company. Unfortunately, the CRSP tapes, which provide bid-ask quotes for NYSE and AMEX firms for the later part of 1988, do not contain the appropriate quotes. The listed bid-ask quotes are not inside quotes at the end of the day, but the lowest bid and highest ask during the day. The 1989 NASDAQ tapes suffer from the same problem. Hence, even for our NASDAQ sample we use the 1988 tapes, which have the correct inside quotes listed at the end of the trading day.
} 
The above estimates for NYSE and AMEX firms are averages and are based on (3b) which shows that the spurious volatility generated by bid-ask errors is equal to $s^{2} / 2$. However, because bid-ask data are lacking, we cannot calculate the $\operatorname{VRD}(k)$ ratios for each security on the NYSE and AMEX and then average cross-sectionally. We can only present approximate values based on average spreads for particular classes of stocks on the NYSE and AMEX. Nevertheless, the estimated proportions suggest that measurement errors due to the bid-ask effect are likely to generate substantial spurious autocorrelation and volatility in short-horizon transaction returns.

With the increasing use of intraday data, this problem is likely to worsen. Measurement errors due to the bid-ask effect could be a predominant source of variation in, for example, hourly returns. Also, as indicated by our daily evidence, the problem may not be limited to small firms. ${ }^{8}$ The spurious volatility generated by bid-ask errors will reduce the power of tests of financial models. For example, in event studies, the gains in power from narrowing the event window by using high-frequency data may be offset by a corresponding increase in the proportion of spurious volatility in measured returns. ${ }^{9}$ Similarly, attempts to explain variation in individual security returns are likely to be unsuccessful [see Roll (1988)], partly because of the noise in short-horizon returns.

\subsection{Comparisons with French and Roll (1986)}

There is one important difference between our evidence for NASDAQ firms and the evidence for NYSE and AMEX stocks documented by French and Roll (1986). French and Roll find positive first-order autocorrelations for all but the smallest two quintiles of NYSE and AMEX firms, but all autocorrelations beyond lag 1 , and up to lag 13 , are negative. On the other hand, we find that NASDAQ security returns are negatively autocorrelated primarily at lag 1 ; higher-order autocorrelations are typically positive, though statistically indistinguishable from zero. In addition, French and Roll find that variance ratios up to six-month measurement intervals decline steadily,

\footnotetext{
${ }^{8}$ Although the bid-ask spreads of large firms are much smaller than the spreads of small firms, the spurious volatility generated by the bid-ask effect is still a large proportion of the variance of transaction returns because the variances for large firms are much smaller than the variances for small firms. For example, the average variance of securities in portfolio 1 is three times the average variance of securities in portfolio $3(0.00264$ vs 0.00083$)$.

${ }^{9}$ Because bid-ask errors are likely to be independent across securities [see Conrad, Kaul, and Nimalendran (1990)], estimates of the beta of a security will remain unbiased. The cross-sectional independence of bid-ask errors also implies that the noise in the returns of a portfolio containing a large number of securities is likely to be attenuated. The number of securities necessary to significantly dampen the effects of bid-ask errors on high-frequency portfolio returns, however, remains to be determined empirically.
} 
whereas the variance ratios for NASDAQ firms increase systematically with the measurement interval.

The negative autocorrelations up to lag 13 in the returns of NYSE and AMEX firms remain a puzzle. French and Roll report autocorrelations that are bias-adjusted, and hence are directly comparable to the autocorrelations for NASDAQ firms reported in this paper. Unfortunately, the specific source(s) of these negative autocorrelations cannot be determined until bid-ask quotes for NYSE and AMEX firms (for a reasonable length of time) become available.

Differences in the behavior of the variance ratios over increasing measurement intervals, however, can largely be explained by the corrections for small-sample biases made in this paper, but not by French and Roll. Recall that the small-sample downward bias in the variance ratios increases systematically as the length of the measurement interval increases with respect to the sample size. Since small-sample bias corrections to variance ratios are functions of the measurement interval and sample size only, we made similar corrections to the French and Roll estimates. Their corrected variance ratios also increase systematically as the measurement interval is increased beyond one month. This suggests that the weak negative autocorrelations up to lag 13 for NYSE and AMEX firms, though intriguing, do not have an impact on variance ratios measured over intervals longer than one month. Therefore, as for NASDAQ firms, stock returns of firms on the NYSE and AMEX also contain a positively autocorrelated component that eventually dominates the effects of the negative autocorrelations.

\section{Summary and conclusions}

In this paper, we investigate the relative importance of bid-ask errors and overreaction in determining the time-series properties of short-horizon security returns. We document two important findings. First, we show that the main source of price reversals for NASDAQ firms in the short run is the bid-ask spread. There is little evidence of market overreaction. On the contrary, once we extract the measurement errors in prices duc to the spread, we find that security returns are positively, and not negatively, autocorrelated. This analysis suggests that the positive profits earned by contrarian strategies could largely be due to a combination of the asymmetric (positive) lead-lag relations in returns and price reversals due to the bid-ask effect. Of course, a more detailed investigation is necessary to test the validity of this conjecture, particularly since profits from contrarian strategies are positive even when weights beyond lag 1 are used in constructing arbitrage portfolios of NYSE and AMEX stocks. Such an investigation is the topic of our future research. 
We also show that computed variances of transaction returns are substantialiy upward biased because of the spurious volatility induced by the bid-ask spread. The bid-ask error component of transaction returns can explain over $50 \%$ of daily return variances. The problem is likely to be even more severe in intraday data. The spurious volatility generated by the bid-ask effect does not vary with the measurement interval, but the volatility of 'true' returns is likely to decrease systematically with the shortening of the measurement interval. Consequently, even larger proportions of the volatility of (say) hourly returns are likely to be spurious. Therefore, if bid-ask prices are available, return series constructed using bid, ask, or the average of bid-ask prices could result in more reliable inferences. Such series have the additional advantage of attenuating the biases in estimates of the mean of security returns [see Blume and Stambaugh (1983) and Keim (1989)].

\section{Appendix}

\section{A.1. Correction for small-sample biases}

We use some refinements to correct for potential small-sample biases in the variance ratio estimator, $\operatorname{VR}(k)$. First, we use overlapping $k$-period returns to estimate the $k$-period variance in the numerator of (7). Use of such overlapping data increases the number of sample observations, and thus enhances the power of our tests.

Second, we obtain unbiased estimators of the one-period and $k$-period variances by appropriate adjustments for degrees of freedom. In particular,

$$
\begin{aligned}
& \widehat{\operatorname{var}}\left(R_{t}^{k}\right)=\frac{1}{m(1-k / n)} \sum_{j=k}^{n}\left(R_{t}^{k}-\hat{\mu}^{k}\right)^{2}, \\
& \widehat{\operatorname{var}}\left(R_{t}\right)=\frac{1}{q-1} \sum_{j=1}^{n}\left(R_{t}-\hat{\mu}\right)^{2},
\end{aligned}
$$

where

$m=$ actual number of overlapping $k$-period observations,

$n=$ number of one-period (daily) measurement intervals in the sample period,

$q=$ actual number of one-period (daily) observations in the sample.

Since weekend returns are over a three-day interval, $n$ and $q$ will not be equal. The degrees-of-freedom adjustments are particularly critical for the estimator of the $k$-period variance in small samples [see Lo and MacKinlay (1989)]. 
Finally, we correct for a downward bias in $\operatorname{VR}(k)$ that may arise, particularly in small samples. Moran (1948) shows that even under the assumption that returns are serially independent, the expected value of the estimated autocorrelations is $-1 /(T-1)$, where $T$ is the number of observations used to estimate the autocorrelations [see also Kendall and Stuart (1976)]. Hence, even if daily returns are serially independent, the estimated variance ratio will be less than unity, that is, using (7),

$$
\mathrm{E}[\mathrm{VR}(k)] \simeq 1-\frac{2}{T-1} \sum_{j=1}^{k-1}\left(\frac{k-j}{k}\right)
$$

From (A.3) it can be seen that the estimated variance ratios can be substantially less than unity if the sample is small, and particularly when the measurement interval, $k$, increases with respect to the sample size. We correct all our reported variance-ratio statistics for this small-sample bias by dividing the estimated variance ratio by $\mathrm{E}[\operatorname{VR}(k)]$ evaluated using (A.3). Kim, Nelson, and Startz (1988) and Poterba and Summers (1988) use similar corrections.

Recall that we also calculate autocorrelations of each return series used in this study, namely, $R_{\mathrm{T} t}, R_{\mathrm{B} t}$, and $R D_{t}$. Each autocorrelation estimate of $R_{\mathrm{T} t}$ and $R_{\mathrm{B} t}$ is corrected for small-sample bias by increasing it by $1 /(T-1)$. Under the hypothesis that bid-ask errors are independent over time, however, $R D_{t}$ will follow an MA(1) process. The expected values of estimators of autocorrelations of $R D_{t}$ under this null hypothesis will not be $-1 /(T-1)$, but are given by [Kendall and Stuart (1976)]

$$
\begin{aligned}
& \mathrm{E}\left(\hat{\rho}_{1}\right)=\rho_{1}+\frac{1}{T}-\frac{1}{1}\left(1+\rho_{1}\right)\left(4 \rho_{1}^{2}-2 \rho_{1}-1\right), \\
& \mathrm{E}\left(\hat{\rho}_{2}\right)=-\frac{1}{T-2}\left(1+2 \rho_{1}+2 \rho_{1}^{2}\right), \\
& \mathrm{E}\left(\hat{\rho}_{j}\right)=-\frac{1}{T-j}\left(1+2 \rho_{1}\right), \quad \forall j>2 .
\end{aligned}
$$

Under the assumption that the bid-ask errors in transaction prices are independent and identically distributed, $\rho_{1}=-0.50$. We use this value of $\rho_{1}$ to correct for biases in estimated autocorrelations of $R D_{t}$.

\section{A.2. The role of weekends}

One important inconsistency in estimates of the autocorrelations and variance ratios is that the one-week variance ratios, for example, are too low 
compared with those implied by the autocorrelations. In table 2 , the one-week variance ratio for portfolio 1 is 0.656 , whereas the ratio implied by the autocorrelations in table 4 is approximately 0.85 [see (7)]. Similarly, the one-week variance ratio of bid returns of small firms in table 3 is 0.932 , whereas the estimated autocorrelations in table 5 imply a ratio greater than unity. These differences are large enough to warrant further investigation.

One likely explanation for the relatively small one-week variance ratios, and thus the apparent existence of overreaction at the one-week interval using bid returns, is that weekend variances are substantially lower than trading-day variances. As argued by French and Roll (1986) and Barclay, Litzenberger, and Warner (1990), the lower-weekend volatilities are caused by lack of private-information-based trading, rather than by market overreaction. To investigate the impact of weekends on variance ratios measured over short intervals, we compute the ratios for intervals up to one week. The general procedure is identical to the procedure used in tables 2 and 3.

Variance ratios for one- to six-day intervals based on transaction and bid returns are reported in tables 8 and 9. Panel A (of both tables) contains estimates based on overlapping observations that include all weekends, and panel B reports estimates of three- and four-day variance ratios based on nonweekend observations only.

The results in tables 8 and 9 have several important features. First, the weekend variances of security returns are substantially lower than trading-day variances. For example, for all firms in our sample, the per-day variance over the weekends is only $37.4 \%$ of the typical trading-day variance (see table 8 , column 2). These findings are consistent with the evidence reported by French and Roll (1986) and Barclay, Litzenberger, and Warner (1990). Second, the lower weekend variances have a significant impact on variance ratios calculated over short intervals. The two-day variance ratios of transaction returns are less than unity for firms in portfolios 1 and 2 and greater than unity for large firms, whereas the two-day ratios using bid returns are always significantly greater than unity. These estimates are generally consistent with the first-order autocorrelations of transaction and bid returns reported in tables 4 and 5. There is a drastic drop, however, in the three-day variance ratios of both transaction and bid returns, followed by a steady decrease in the four- and five-day ratios. This behavior is consistent with the impact of the lower weekend variances, since one of every three three-day observations, two of every three four-day observations, and all of the five-day observations contain weekends. Hence, it is not surprising that weekends have their maximum effect on the five-day variance ratios. The behaviur of the three- and four-day variance ratios, which are based on only nonweekend observations, confirms the dampening effect of weekends on short-interval variance ratios [see panel B, tables 8 and 9]. Exclusion of weekend observations leads to a dramatic increase in the three- and four-day variance ratios 
Table 8

Variance ratios for measurement intervals of less than one week for NASDAQ stocks using transaction returns, 1983-1987.

Variance ratios for two- to six-day intervals and the variance ratio over the weekends, based on daily returns of all securities and securities belonging to three portfolios formed by rankings of market value of equity outstanding at the beginning of each six-month period. The variance-ratio statistic is defined as $\operatorname{VR}(k)=(1 / k)\left\{\operatorname{var}\left(R^{k}\right) / \operatorname{var}(R)\right\}$, where $R$ and $R^{k}$ denote returns over a daily and a $k$-period measurement interval, respectively. Each variance ratio is corrected for small-sample biases (see appendix). All statistics are estimated for each firm, using overlapping data to calculate the $k$-period variance, during each of the ten six-month subperiods between January 1983 and December 1987. The individual-firm statistics are averaged across firms within each portfolio (and across all firms in the sample) to obtain subperiod averages. Each reported summary statistic is the weighted grand average of the ten subperiod averages. The numbers in parentheses are weighted standard errors based on the distribution of the subperiod averages.

\begin{tabular}{|c|c|c|c|c|c|c|}
\hline \multirow[b]{2}{*}{$\begin{array}{l}\text { NASDAQ } \\
\text { portfolios }\end{array}$} & \multicolumn{6}{|c|}{ Return measurement interval $(k)$} \\
\hline & weekends & $\begin{array}{c}2 \\
\text { day }\end{array}$ & $\begin{array}{c}3 \\
\text { day }\end{array}$ & $\begin{array}{c}4 \\
\text { day }\end{array}$ & $\begin{array}{c}5 \\
\text { day }\end{array}$ & $\begin{array}{c}6 \\
\text { day }\end{array}$ \\
\hline \multicolumn{7}{|c|}{ Panel A: Including weekends } \\
\hline $\begin{array}{l}1 \\
\text { (smallest) }\end{array}$ & $\begin{array}{c}0.350 \\
(0.012)\end{array}$ & $\begin{array}{c}0.906 \\
(0.021)\end{array}$ & $\begin{array}{c}0.725 \\
(0.019)\end{array}$ & $\begin{array}{c}0.628 \\
(0.015)\end{array}$ & $\begin{array}{c}0.572 \\
(0.013)\end{array}$ & $\begin{array}{c}0.630 \\
(0.015)\end{array}$ \\
\hline 2 & $\begin{array}{c}0.374 \\
(0.019)\end{array}$ & $\begin{array}{c}0.968 \\
(0.021)\end{array}$ & $\begin{array}{c}0.782 \\
(0.018)\end{array}$ & $\begin{array}{c}0.690 \\
(0.014)\end{array}$ & $\begin{array}{c}0.645 \\
(0.019)\end{array}$ & $\begin{array}{c}0.711 \\
(0.013)\end{array}$ \\
\hline $\begin{array}{l}3 \\
\text { (largest) }\end{array}$ & $\begin{array}{c}0.382 \\
(0.021)\end{array}$ & $\begin{array}{c}1.061 \\
(0.020)\end{array}$ & $\begin{array}{c}0.878 \\
(0.013)\end{array}$ & $\begin{array}{c}0.791 \\
(0.015)\end{array}$ & $\begin{array}{c}0.743 \\
(0.022)\end{array}$ & $\begin{array}{c}0.829 \\
(0.012)\end{array}$ \\
\hline All firms & $\begin{array}{c}0.374 \\
(0.011)\end{array}$ & $\begin{array}{c}1.005 \\
(0.016)\end{array}$ & $\begin{array}{c}0.821 \\
(0.014)\end{array}$ & $\begin{array}{c}0.730 \\
(0.014)\end{array}$ & $\begin{array}{c}0.682 \\
(0.017)\end{array}$ & $\begin{array}{c}0.757 \\
(0.016)\end{array}$ \\
\hline \multicolumn{7}{|c|}{ Panel B: Excluding weekends } \\
\hline $\begin{array}{l}1 \\
\text { (smallest) }\end{array}$ & & & $\begin{array}{c}0.895 \\
(0.031)\end{array}$ & $\begin{array}{c}0.897 \\
(0.038)\end{array}$ & & \\
\hline 2 & & & $\begin{array}{c}0.970 \\
(0.030)\end{array}$ & $\begin{array}{c}0.974 \\
(0.033)\end{array}$ & & \\
\hline $\begin{array}{l}3 \\
\text { (largest) }\end{array}$ & & & $\begin{array}{c}1.108 \\
(0.028)\end{array}$ & $\begin{array}{c}1.147 \\
(0.022)\end{array}$ & & \\
\hline All firms & & & $\begin{array}{c}1.027 \\
(0.023)\end{array}$ & $\begin{array}{c}1.048 \\
(0.025)\end{array}$ & & \\
\hline
\end{tabular}

based on both transaction and bid returns. More importantly, all ratios based on bid returns are greater than unity and increase systematically as the measurement interval is increased from two to four days.

Finally, the pattern in the five-day to one-week ratios of bid returns suggests that market overreaction is an unlikely cause of one-week ratios being less than unity. These ratios increase steadily, and the one-week ratio for large firms is not significantly different from unity. This increase is consistent with the private-information hypothesis suggested by French and 
Table 9

Variance ratios for measurement intervals of less than one week for NASDAQ stocks using bid-to-bid returns, 1983-1987.

Variance ratios for two- to six-day intervals and the variance ratio over the weekends, based on daily returns of all securities and securities belonging to three portfolios formed by rankings of market value of equity outstanding at the beginning of each six-month period. The variance-ratio statistic is defined as $\operatorname{VR}(k)=(1 / k)\left\{\operatorname{var}\left(R^{k}\right) / \operatorname{var}(R)\right\}$, where $R$ and $R^{k}$ denote returns over a daily and a $k$-period measurement interval, respectively. Each variance ratio is corrected for small-sample biases (see appendix). All statistics are estimated for each firm, using overlapping data to calculate the $k$-period variance, during each of the ten six-month subperiods between January 1983 and December 1987. The individual-firm statistics are averaged across firms within each portfolio (and across all firms in the sample) to obtain subperiod averages. Each reported summary statistic is the weighted grand average of the ten subperiod averages. The numbers in parentheses are weighted standard errors based on the distribution of the subperiod averages.

\begin{tabular}{|c|c|c|c|c|c|c|}
\hline \multirow[b]{2}{*}{$\begin{array}{l}\text { NASDAQ } \\
\text { portfolios }\end{array}$} & \multicolumn{6}{|c|}{ Return measurement interval $(k)$} \\
\hline & weekends & $\begin{array}{c}2 \\
\text { day }\end{array}$ & $\begin{array}{c}3 \\
\text { day }\end{array}$ & $\begin{array}{c}4 \\
\text { day }\end{array}$ & $\begin{array}{c}5 \\
\text { day }\end{array}$ & $\begin{array}{c}6 \\
\text { day }\end{array}$ \\
\hline \multicolumn{7}{|c|}{ Panel A: Including weekends } \\
\hline $\begin{array}{l}1 \\
\text { (smallest) }\end{array}$ & $\begin{array}{c}0.404 \\
(0.043)\end{array}$ & $\begin{array}{c}1.105 \\
(0.021)\end{array}$ & $\begin{array}{c}0.922 \\
(0.021)\end{array}$ & $\begin{array}{c}0.837 \\
(0.021)\end{array}$ & $\begin{array}{c}0.791 \\
(0.029)\end{array}$ & $\begin{array}{c}0.891 \\
(0.027)\end{array}$ \\
\hline 2 & $\begin{array}{c}0.393 \\
(0.023)\end{array}$ & $\begin{array}{c}1.122 \\
(0.024)\end{array}$ & $\begin{array}{c}0.931 \\
(0.017)\end{array}$ & $\begin{array}{c}0.841 \\
(0.012)\end{array}$ & $\begin{array}{c}0.800 \\
(0.019)\end{array}$ & $\begin{array}{c}0.902 \\
(0.010)\end{array}$ \\
\hline $\begin{array}{l}3 \\
\text { (largest) }\end{array}$ & $\begin{array}{c}0.394 \\
(0.023)\end{array}$ & $\begin{array}{c}1.158 \\
(0.025)\end{array}$ & $\begin{array}{c}0.975 \\
(0.015)\end{array}$ & $\begin{array}{c}0.889 \\
(0.014)\end{array}$ & $\begin{array}{c}0.843 \\
(0.021)\end{array}$ & $\begin{array}{c}0.952 \\
(0.012)\end{array}$ \\
\hline All firms & $\begin{array}{c}0.396 \\
(0.016)\end{array}$ & $\begin{array}{c}1.137 \\
(0.014)\end{array}$ & $\begin{array}{c}0.952 \\
(0.011)\end{array}$ & $\begin{array}{c}0.864 \\
(0.010)\end{array}$ & $\begin{array}{c}0.820 \\
(0.013)\end{array}$ & $\begin{array}{c}0.925 \\
(0.010)\end{array}$ \\
\hline
\end{tabular}

Panel B: Excluding weekends

$\begin{array}{lcc}1 & 1.166 & 1.219 \\ \text { (smallest) } & (0.031) & (0.039) \\ 2 & 1.185 & 1.224 \\ & (0.034) & (0.035) \\ 3 & 1.248 & 1.311 \\ \text { (largest) } & (0.034) & (0.030) \\ \text { All firms } & 1.213 & 1.267 \\ & (0.020) & (0.021)\end{array}$

Roll (1986), which predicts that the effects of lower weekend variances should be dissipated over long measurement intervals.

\section{References}

Amihud, Yakov and Haim Mendelson, 1987, Trading mechanisms and stock returns: An empirical investigation, Journal of Finance 42, 533-553.

Barclay, Michael J., Robert H. Litzenberger, and Jerold B. Warner, 1990, Private information, trading volumc, and stock rcturn variances, Review of Financial Studies 3, 233253.

Blume, Marshall E. and Robert F. Stambaugh, 1983, Biases in computed returns: An application to the size effect, Journal of Financial Economics 12, 387-404. 
Cochrane, John H., 1988, How big is the random walk in GNP?, Journal of Political Economy 96, 893-920.

Cohen, Kalman J., Steven F. Maier, Robert A. Schwartz, and David K. Whitcomb, 1986, The microstructure of securities markets (Prentice-Hall, Englewood Cliffs, NJ).

Conrad, Jennifer and Gautam Kaul, 1988, Time-variation in expected returns, Journal of Business $61,409-425$.

Conrad, Jennifer and Gautam Kaul, 1989, Mean-reversion in short-horizon expected returns, Review of Financial Studies 2, 225-240.

Conrad, Jennifer, Mustafa Gultekin, and Gautam Kaul, 1990, The profitability and riskiness of contrarian portfolio strategies, Working paper (University of North Carolina, Chapel Hill, $\mathrm{NC}$.

Conrad, Jennifer, Gautam Kaul, and M. Nimalendran, 1990, Components of short-horizon individual security returns, Working paper (University of Michigan, Ann Arbor, MI).

DeBondt, Werner and Richard Thaler, 1985, Does the stock market overreact?, Journal of Finance 40, 793-805.

DeLong, J. Bradford, Andrei Shleifer, Lawrence H. Summers, and Robert J. Waldman, 1990, Positive feedback investment strategies and destabilizing rational speculation, Journal of Finance 45, 379-395.

Fama, Eugene F., 1965, The behavior of stock market prices, Journal of Business 38, 34-105.

Fama, Eugene F. and Kenneth R. French, 1988, Permanent and temporary components of stock prices, Journal of Political Economy 96, 246-273.

French, Kenneth R. and Richard Roll, 1986, Stock return variances: The arrival of information and the reaction of traders, Journal of Financial Economics 17, 5-26.

George, Thomas J., Gautam Kaul, and M. Nimalendran, 1990, Estimation of the bid-ask spread and its components: A new approach, Working paper (The University of Michigan, Ann Arbor, MI).

Glosten, Lawrence R., 1987, Components of the bid-ask spread and the statistical properties of transaction prices, Journal of Finance 42, 1293-1308.

Keim, Donald B., 1989, Trading patterns, bid-ask spreads, and estimated security returns: The case of common stocks at calender turning points, Journal of Financial Economics 25, 75-97.

Kendall, Maurice G. and Allen Stuart, 1976, The advanced theory of statistics, Vol. 3, 3rd ed. (Griffin, London).

Kim, Myung J., Charles R. Nelson, and Richard Startz, 1988, Mean reversion in slock prices? A reappraisal of the empirical evidence, Working paper (NBER, Cambridge, MA).

Lehmann, Bruce N., 1990, Fads, martingales, and market efficiency, Quarterly Journal of Economics 105, 1-28.

Lo, Andrew W. and A. Craig MacKinlay, 1988, Stock market prices do not follow random walks: Evidence from a simple specification test, Review of Financial Studies 1, 41-66.

Lo, Andrew W. and A. Craig MacKinlay, 1989, The size and power of the variance ratio test in finite samples: A Monte Carlo investigation, Journal of Econometrics 40, 203-238.

Lo, Andrew W. and A. Craig MacKinlay, 1990, When are contrarian profits due to stock market overreaction?, Review of Financial Studies 3, 175-205.

Moran, P.A.P., 1948, Some theorems on time series, Biometrika 35, 255-260.

Niederhoffer, Victor and M.F.M. Osbonne, 1966, Market making and reversal on the slock exchange, Journal of the American Statistical Association 61, 897-916.

Poterba, James M. and Lawerence H. Summers, 1988, Mean reversion in stock prices: Evidence and implications, Journal of Financial Economics 22, 27-60.

Roll, Richard, 1984, A simple implicit measure of the effective bid-ask spread in an efficient market, Journal of Finance 39, 1127-1140.

Roll, Richard, 1988, $R^{2}$, Journal of Finance 43, 541-566.

Scholes, Myron and Joseph Williams, 1977, Estimating beta from nonsynchronous data, Journal of Financial Economics 5, 309-327.

Shefrin, Hersh and Meir Statman, 1985, The disposition to ride winners too long and sell losers too soon: Theory and evidence, Journal of Finance 41, 774-790.

Summers, Lawerence H., 1986, Does the stock market rationally reflect fundamental values?, Journal of Finance 41, 591-600. 